\title{
Identifikasi Degradasi Tanah dan Pengaruh Faktor Penggunaan Lahan Terhadap Degradasi Tanah pada Semak Belukar dan Hutan Sekunder di Kecamatan Kairatu Kabupaten Seram Bagian Barat Propinsi Maluku
}

\author{
Soil Degradation Identification and the Effects of Land Use Factor on Soil Degradation in Shrubs \\ and Secondary Forest in the District of Kairatu West Seram Regency, Maluku Province
}

\section{Silwanus M. Talakua}

\author{
Jurusan Budidaya Pertanian, Fakultas Pertanian, Universitas Pattimura, Jl. Ir. M. Putuhena, Kampus Poka Ambon \\ 97233 \\ *E-mail Penulis Korespondensi: silwanustalakua@yahoo.com
}

\begin{abstract}
The results showed that the average soil degradation in shrubs was 285.57 t/ha/yr, higher than secondary forests, i.e 4.39 t/ha/yr. Indicators of soil degradation in shrubs were pedestals, root plant exposure, rills, and gully, while in secondary forests are pedestals and plant/tree roots exposure. Individually, the extent of land use, the density of upper vegetation and the density of lower vegetation had significant effects on the soil degradation in shrubs and secondary forests. Simultaneously, the extent of land use, the density of upper and lower vegetation had significant effects on soil degradation in shrub and secondary forests. The factor that had the greatest effect on soil degradation in shrubs and secondary forests was the density of upper and lower vegetation.
\end{abstract}

Keywords: density of upper vegetation, the density of lower vegetation, shrub and secondary forest, soil degradation, the extent of land use

\section{ABSTRAK}

Hasil penelitian menunjukkan bahwa besar degradasi tanah rata-rata pada semak belukar adalah 285,57 t/ha/thn lebih tinggi dibandingkan hutan sekunder sebesar 4,39 t/ha/thn. Indikator degradasi tanah pada semak belukar adalah pedestal, akar tanaman terekspos, alur dan parit, sedangkan pada hutan sekunder adalah pedestal dan akar tanaman/pohon terekspos. Secara tunggal, luas penggunaan lahan, kerapatan vegetasi atas dan kerapatan vegetasi bawah berpengaruh nyata terhadap degradasi tanah pada penggunaan lahan semak belukar dan hutan sekunder. Secara serempak, luas penggunaan lahan, kerapatan vegetasi atas dan kerapatan vegetasi bawah berpengaruh nyata terhadap degradasi tanah pada penggunaan lahan semak belukar dan hutan sekunder. Faktor yang paling berpengaruh terhadap degradasi tanah pada semak belukar dan hutan sekunder adalah kerapatan vegetasi atas dan kerapatan vegetasi bawah.

Kata Kunci: degradasi tanah, kerapatan vegetasi atas, kerapatan vegetasi bawah, luas penggunaan lahan, semak belukar dan hutan sekunder

\section{PENDAHULUAN}

Penggunaan lahan merupakan istilah yang digunakan untuk menjelaskan peranan manusia dalam menggunakan lahan, atau tindakan-tindakan yang dengan segera memodifikasi atau mengubah penutup lahan, atau dengan kata lain pola penggunaan lahan merupakan pencerminan dari kegiatan-kegiatan manusia yang ada di atasnya. Penggunaan lahan dapat secara alamiah seperti hutan primer maupun yang terbentuk sebagai akibat intervensi manusia seperti hutan sekunder. Menurut Sandy (1977), pengertian hutan lebat terutama ditentukan oleh jenis tanaman hutan yang tampak sebagai hutan lebat, baik yang tumbuh secara alami ataupun yang dipelihara. Sedangkan hutan belukar adalah tanah yang ditumbuhi semak-semak terutama berbatang kecil. Mungkin tanah bekas ladang, atau semak-semak itu merupakan tanaman sisa daripada hutan yang lebih lebat, yang pohon-pohonnya berbatang besar telah ditebang.

Sedangkan menurut FAO (1995), hutan alam memiliki batasan yaitu peruntukan lahan ditetapkan sebagai kawasan hutan dan perkembangan vegetasi hutan sebagai habitat binatang-binatang hutan. Tujuan penggunaan lahan untuk wahana konservasi tanah dan air, media produksi komoditi hasil hutan dan pelestarian plasma nutfah. Jenis vegetasi penutup lahan bervariasi didominasi oleh vegetasi pepohonan. 
Hutan tanaman memiliki batasan yaitu peruntukan lahan sebagai kawasan hutan tempat tumbuh dan berkembangnya vegetasi hutan yang dibudidayakan. Tujuan penggunaan lahan sebagai media produksi komoditi hasil hutan berupa kayu dan hasil sampingan. Jenis vegetasi penutup lahan terdiri dari jenis pepohonan sejenis.

Penggunaan lahan merupakan faktor yang paling rentan dan selalu menjadi sasaran utama terhadap pengaruh perubahan oleh manusia dibandingkan dengan faktor-faktor lain seperti iklim, tanah, dan topografi.

Akibat dari adanya campur tangan manusia dalam perubahan tersebut, maka terbentuklah berbagai tipe penggunaan lahan antara lain: areal yang dilindungi seperti hutan primer dan sekunder; Apabila komponen penggunaan lahan berubah terutama penggunaan lahan hutan (deforestasi) maka akan terjadi perubahan ekosistem, yang berdampak pada perubahan siklus hidrologi. Perubahan siklus hidrologi akan mengakibatkan aliran permukaan lebih besar dari infiltrasi sehingga selanjutnya akan menyebabkan kerusakan tanah karena erosi air.

Menurut International Soil Reference and Information Centre/United Nations Environment Programme ISRIC/UNEP (1991), United Nations (1994 dikutip FAO, 1996) tipe kerusakan lahan di Indonesia yang terbesar disebabkan oleh erosi air (80\%), sedangkan sisanya masing-masing oleh degradasi kimia sebesar $15 \%$ dan degradasi fisik sebesar 5\%. Apabila ditinjau dari aspek penyebabnya, maka di Indonesia penyebab kerusakan lahan yang terbesar adalah oleh deforestasi sebesar $63 \%$ dan sisanya oleh aktivitas pertanian sebesar $37 \%$.

Lahan kritis untuk Kabupaten Maluku Tengah antara tahun 1987 sampai tahun 1989 terjadi peningkatan luas yaitu dari 19.045 ha menjadi 45.401 ha (bertambah sebesar 26.356 ha), sedangkan untuk Kecamatan Kairatu dan Piru yang di dalamnya terdapat daerah penelitian, luas lahan kritis bertambah dari 10.845 ha pada tahun 1987 menjadi 18.825 ha pada tahun 1989 atau mengalami peningkatan sebesar 73,6\% (Badan Perencanaan Pembangunan Daerah Propinsi Maluku, 1996).

Meningkatnya lahan kritis di Kecamatan Kairatu, mengindikasikan telah terjadi pengurangan luas penggunaan lahan hutan, karena dikonversi untuk penggunaan lahan kebun campuran/perkebunan, ladang, permukiman, serta munculnya lahan-lahan marginal seperti semak belukar dan alang-alang, dengan tingkat kerapatan vegetasi atas dan kerapatan vegetasi bawah yang semakin berkurang.

\section{BAHAN DAN METODE PENELITIAN}

\section{Lokasi dan Waktu Penelitian}

Penelitian ini dilaksanakan di Kecamatan Kairatu Kabupaten Seram Bagian Barat Propinsi Maluku dengan luas $12.685,81$ ha dan secara geografis terletak pada $3^{\circ} 06^{\prime} 01^{\prime \prime}-3^{\circ} 27^{\prime} 10^{\prime \prime} \quad$ Lintang Selatan dan $128^{\circ} 18^{\prime} 57^{\prime \prime}-128^{\circ} 42^{\prime} 05^{\prime \prime}$ Bujur Timur.

Penelitian ini berlangsung dari tahun 2006 sampai tahun 2007 yang dimulai dengan pengumpulan data, observasi, penelitian lapangan, analisis laboratorium dan pengolahan data sampai penulisan laporan.

\section{Penentuan Titik Pengamatan}

Penentuan titik pengamatan pada lokasi penelitian dilakukan berdasarkan Peta Unit Lahan skala 1:100.000. Pada penelitian ini dikaji efek luas penggunaan lahan $\left(X_{1}\right)$, kerapatan vegetasi atas $\left(X_{2}\right)$, dan kerapatan vegetasi bawah $\left(X_{3}\right)$ terhadap degradasi tanah $(Y)$, pada semak belukar dan hutan sekunder, oleh karena itu dibuat area pengamatan dengan mengelompokan unit-unit lahan yang memiliki penggunaan lahan yang berbeda tetapi memiliki kelas topografi dan jenis geologi, klasifikasi asosiasi tanah dan kelompok iklim yang sama, dengan jumlah area pengamatan $(n)$ adalah sembilan.

\section{Pengukuran Variabel-Variabel Penelitian}

Karakteritik penggunaan lahan dalam hal ini luas $\left(X_{I}\right)$, penyebaran vegetasi dan kerapatan vegetasi atas didapat dari hasil analisis penginderaan jauh citra satelit Landsat False Colour Composite TM Tahun 1992 dan False Colour Composite MSS Tahun 1990 oleh Dinas Kehutanan Propinsi Maluku (Dinas Kehutanan Propinsi Maluku, 1994), maupun hasil penelitian lapangan. Setelah ditentukan jenis penggunaan lahan dan penyebarannya, maka selanjutnya diukur masingmasing tipe penggunaan lahan sesuai titik pengamatan dengan menggunakan planimeter dalam satuan luas yaitu hektar (ha). Pengukuran variabel kerapatan vegetasi atas $\left(X_{2}\right)$ dan kerapatan vegetasi bawah $\left(X_{3}\right)$ pada penggunaan lahan kebun campuran dan semak belukar adalah sesuai titik pengamatan di lapangan yaitu dengan mengukur luas area penutupan tajuk untuk vegetasi bawah, kemudian dibandingkan terhadap luas area pengamatan, sehingga didapat persentasi tingkat kerapatan vegetasi atas dan bawah berdasarkan formula yang dikemukakan oleh Swiecki dan Bernhardt (2001) dan Dissmeyer dan Foster (1980). Pengukuran erosi tanah berdasarkan panduan oleh Stocking dan Murnaghan (2000) sesuai jumlah titik pengamatan.

\section{Analisis Laboratorium}

Untuk penentuan kerusakan tanah akibat erosi aktual melalui pengukuran indikator erosi tanah di lapangan, maka yang dianalisis adalah tekstur tanah (meliputi kandungan pasir kasar - pasir sangat halus, debu dan liat) (metode pipet), bobot isi tanah (metode gravimetri), C-organik (metode metode Walkley and Black) untuk penentuan kandungan bahan organik dan permeabilitas profil tanah yang dilaksanakan di 
Laboratorium Departemen Tanah dan Sumberdaya Lahan Fakultas Pertanian Institut Pertanian Bogor.

\section{Analisis Data}

Hubungan antara variabel-variabel $Y$ dan $X$ pada tiap area pengamatan (unit lahan) di lokasi penelitian dapat dinyatakan dalam model regresi linier, non linier (berpangkat, eksponensial, logaritma, subordo kedua dan subordo ketiga), serta regresi berganda (Morrison, 1976; Draper dan Smith, 1992). Model regresi linier secara umum adalah:

$$
Y_{i}=\beta_{o}+\beta_{1} X_{i j}+\varepsilon_{i}
$$

Keterangan: $Y_{i}=$ Variabel terikat yaitu erosi tanah (t/ha/tahun). $X_{i j}=$ Variabel-variabel bebas yaitu: luas (ha), kerapatan vegetasi atas (\%), dan kerapatan vegetasi bawah (\%) pada kebun campuran dan semak belukar; $\beta_{1}=$ koefisien regresi; $\beta_{\mathrm{o}}=$ koefisien intersep; $\varepsilon_{\mathrm{i}}$ $=$ galat.

\section{HASIL DAN PEMBAHASAN}

Indikator dan Besar Degradasi Tanah pada Penggunaan Lahan Semak Belukar dan Hutan Sekunder

Hasil penelitian dan sidik ragam menunjukkan bahwa besar degradasi tanah untuk semak belukar (sebesar 285,57 ton/ha/thn) lebih tinggi dibandingkan dengan hutan sekunder $(4,39$ ton/ha/thn $)$ dengan perbedaan yang nyata (nilai $\mathrm{P}=0,005^{*}$ ) di daerah penelitian. Indikator degradasi tanah yang terjadi pada semak belukar adalah tinggi pedestal rata-rata 1,76 $\mathrm{mm} / \mathrm{thn}$, akar terekspos $2,78 \mathrm{~mm} / \mathrm{thn}$, kedalaman alur $0,9 \mathrm{~cm} / \mathrm{thn}$, kedalaman parit $0,14 \mathrm{~m} / \mathrm{thn}$, lebih tinggi dibandingkan dengan indikator pada hutan sekunder yaitu tinggi pedestal $0,42 \mathrm{~mm} / \mathrm{thn}$, akar terekspos 0,46 $\mathrm{mm} /$ thn (Gambar 1 dan Gambar 2).

Hal ini dapat dijelaskan bahwa penggunaan lahan berpengaruh nyata terhadap degradasi tanah, dalam hal ini erosi air. Adanya vegetasi yang baik (hutan sekunder) mampu mengintersep sebagian besar curah hujan yang jatuh, selanjutnya air hujan yang terintersep pada permukaan vegetasi tersebut sebagian mengalami proses evaporasi kembali ke atmosfir, dibandingkan vegetasi yang buruk (semak belukar). Penggunaan lahan semak belukar terbentuk akibat penebangan areal hutan (konversi lahan hutan), telah menyebabkan rusaknya struktur vegetasi alami baik luas lahan, kerapatan vegetasi atas dan bawah menyebabkan meningkatnya degradasi tanah yang diindikasikan dengan terbentuknya pedestal, akar tanaman/pohon terekspos, alur dan parit. Hal ini sejalan dengan Majule (2003) yang mengemukakan bahwa erosi tanah merupakan fungsi dari penggunaan lahan. Menurut FAO (1999b) kehilangan penutup tanah akan mengintensifkan kerusakan tanah khususnya pada lereng-lereng curam, karena terjadi peningkatan erosi dan aliran permukaan yang ditunjukkan dengan adanya erosi alur dan parit yang sangat besar.

\section{Pengaruh Faktor Luas Penggunaan Lahan terhadap Degradasi Tanah pada Semak Belukar dan Hutan Sekunder}

Berdasarkan hasil penelitian dan hasil sidik ragam regresi ternyata bahwa luas penggunaan lahan berpengaruh nyata secara positif terhadap degradasi tanah pada semak belukar, dengan nilai $\mathrm{P}=0,044^{*}$, serta memiliki koefisien korelasi positif yaitu $+0,88$. Sebaliknya pada hutan sekunder berpangaruh negatif dengan nilai $\mathrm{P}=0,022 *$ serta koefisien korelasi negatif $-0,77$ seperti disajikan pada Gambar 3 .
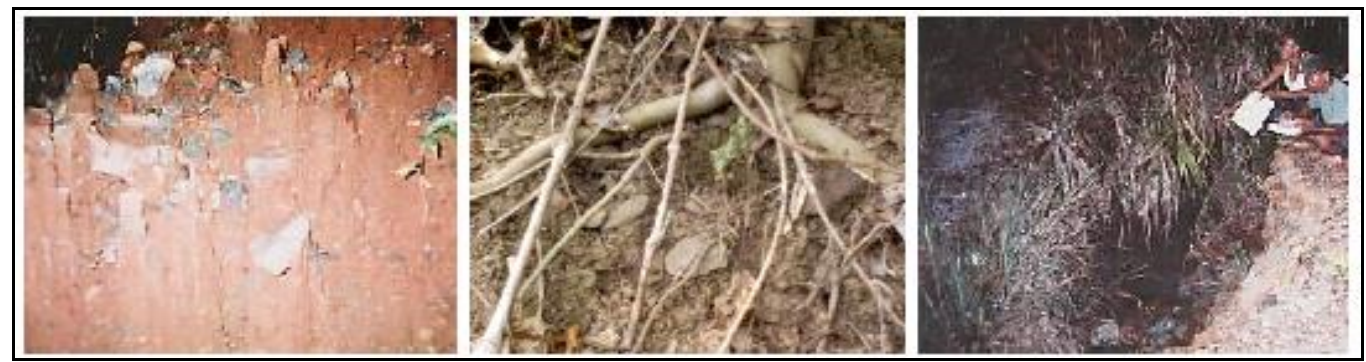

Gambar 1. Indikator degradasi tanah pada penggunaan lahan semak belukar di Kecamatan Kairatu (Talakua, 2009)

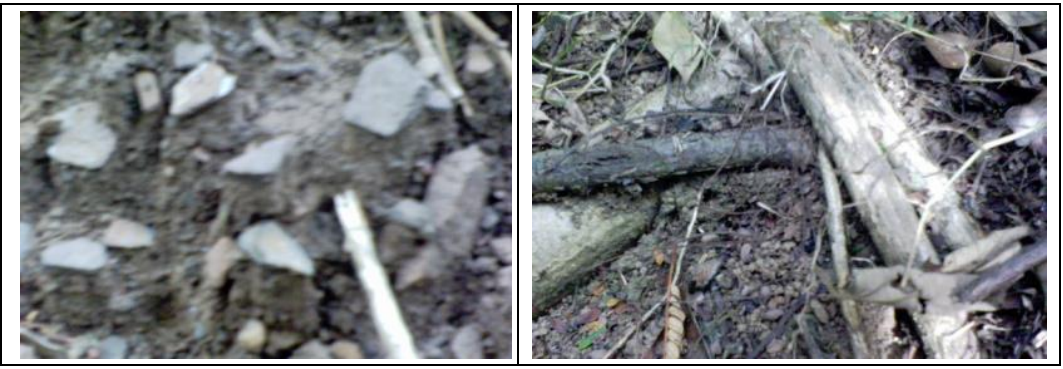

Gambar 2. Indikator degradasi tanah pada penggunaan lahan hutan sekunder di Kecamatan Kairatu (Talakua, 2009) 
Dapat dijelaskan bahwa penggunaan lahan semak belukar merupakan penggunaan lahan hasil konversi dari areal hutan alami. Penggunaan lahan hasil konversi ini mempunyai kerapatan vegetasi dan stratifikasi vegetasi sangat kurang, demikian juga kerapatan vegetasi bawah relatif sangat kurang. Dengan kondisi seperti demikian hujan akan semakin besar langsung jatuh ke tanah dan sangat sedikit terintersep oleh tanaman atau vegetasi. Dengan demikian tingkat degradasi tanah jauh lebih besar dibandingkan dengan hutan sekunder.

Pada penggunaan lahan hutan alami seperti hutan sekunder, dengan semakin luas arealnya terpelihara maka akan menyebabkan kerusakan tanah akibat erosi makin berkurang. Semakin luas areal hutan berarti semakin banyak vegetasi yang berlapis-lapis baik pada tingkat pohon sampai penutup bawah, ini akan menyebabkan semakin tinggi tingkat perlindungan tanah terhadap pukulan butir hujan baik melalui tajuk tanaman, sumbangan lantai hutan maupun peranan zone perakaran vegetasi dalam mengikat agregat tanah. Semakin luas hutan primer dan hutan sekunder maka degradasi tanah melalui peristiwa erosi semakin kecil.

Hal ini sesuai dengan hasil kajian Symeonakis et al. (2004) bahwa penebangan hutan (deforestasi) menjadi penyebab meningkatnya laju aliran permukaan sejak vegetasinya dihilangkan. Dikuatkan juga dengan hasil penelitian Kelompok Kerja Erosi dan Sedimentasi (2002) di Balikpapan Kalimantan Timur menunjukkan bahwa adanya penurunan luasan lahan berhutan dan semakin meningkatnya luasan areal semak belukar dan alang-alang, dapat meningkatkan laju aliran permukaan dan degradasi tanah akibat erosi tanah.

\section{Pengaruh Faktor Kerapatan Vegetasi Atas terhadap Degradasi Tanah pada Penggunaan Lahan Semak Belukar dan Hutan Sekunder}

Berdasarkan hasil penelitian dan hasil sidik ragam regresi ternyata bahwa kerapatan vegetasi atas berpengaruh nyata secara negatif terhadap degradasi tanah pada penggunaan lahan semak belukar dan hutan sekunder, dengan nilai-P 0,000*, serta memiliki koefisien korelasi yang negatif $-0,98$, seperti disajikan pada Gambar 4.

Dari hasil tersebut dapat dilihat bahwa semakin berkurangnya kerapatan vegetasi atas akan menyebabkan degradasi tanah semakin meningkat pada semak belukar maupun hutan sekunder. Dapat dijelaskan bahwa adanya vegetasi yang sangat rapat, terutama strata atas dapat melindungi melalui tajuk vegetasinya yang mampu mengintersep sebagian besar curah hujan yang jatuh, sehingga yang jatuh langsung ke permukaan tanah sangat sedikit sekali dengan energi yang sudah sangat berkurang. Di samping itu juga adanya vegetasi yang semakin rapat pada permukaan tanah mampu memperkecil aliran permukaan dan memperbesar infiltrasi.

Hal ini sesuai dengan hasil penelitian Kokh-Shrestha (2002) di Nepal, yang mengemukakan bahwa kerapatan vegetasi atas berpengaruh terhadap erosi tanah dimana makin berkurangnya kerapatan vegetasi atas maka erosi makin meningkat. Menurut FAO (1999b) terdapat dua komponen dari penutupan tajuk dalam mengurangi erosi yaitu penutup atas (aerial cover) dan penutup bawah (contact cover).

\section{Pengaruh Faktor Kerapatan Vegetasi Bawah Terhadap Degradasi Tanah pada Penggunaan Lahan Semak Belukar dan Hutan Sekunder}

Berdasarkan hasil penelitian dan hasil sidik ragam regresi ternyata bahwa kerapatan vegetasi bawah berpengaruh nyata secara negatif terhadap degradasi tanah pada penggunaan lahan semak belukar dan hutan sekunder, dengan nilai-P masing-masing $0,001 *$ dan $0,042 *$, serta memiliki koefisien korelasi negatif yaitu $-0,91$ dan $-0,71$, seperti yang disajikan pada Gambar 5 . Dari hasil tersebut dapat dilihat bahwa semakin berkurangnya kerapatan vegetasi bawah akan menyebabkan degradasi tanah semakin meningkat pada semak belukar dan hutan sekunder.

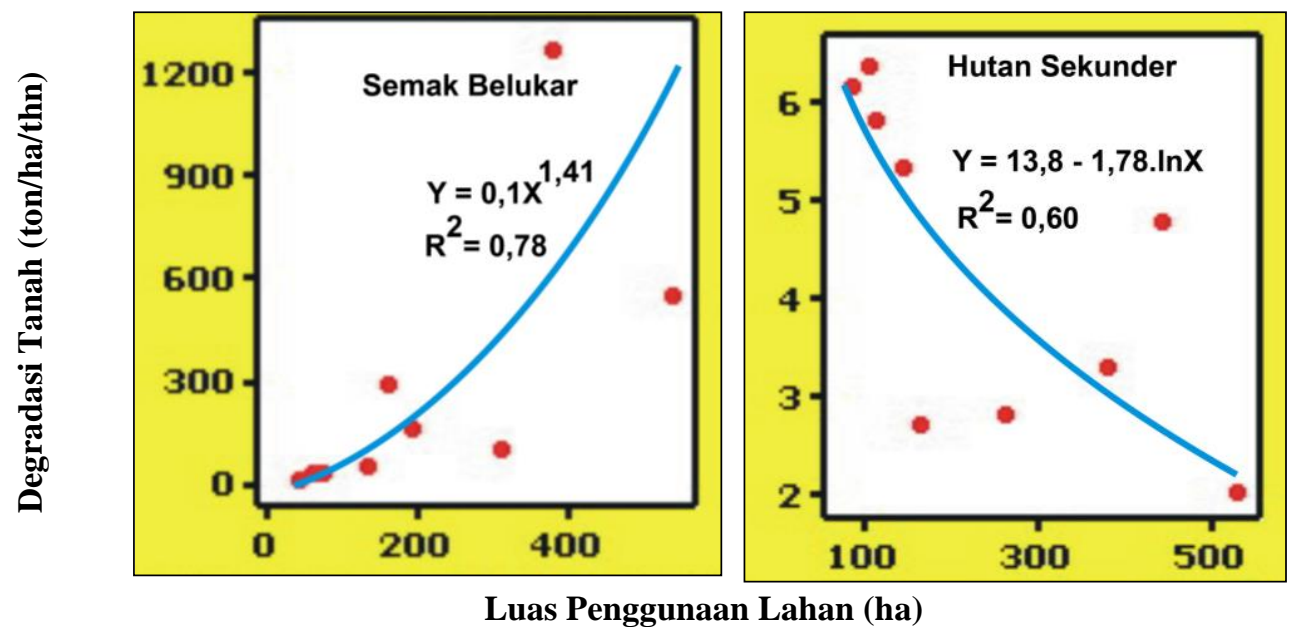

Gambar 3. Pengaruh luas penggunaan lahan terhadap erosi tanah pada penggunaan lahan semak belukar dan hutan sekunder di Kecamatan Kairatu. 


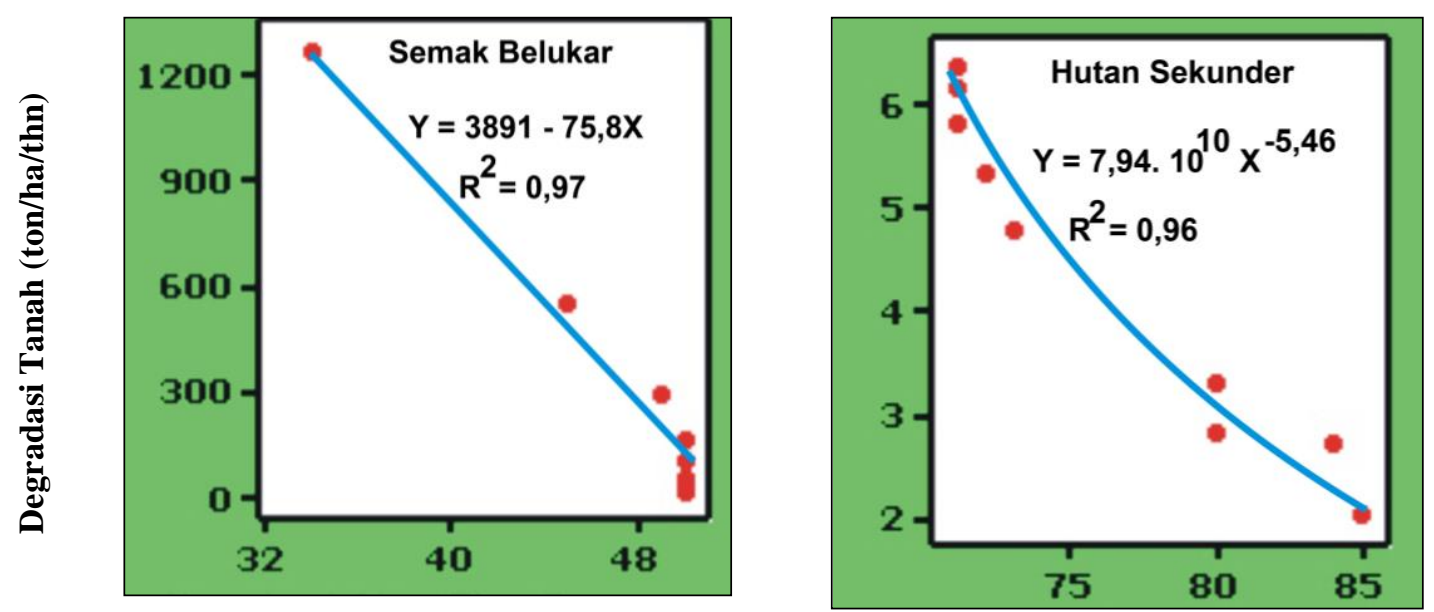

Kerapatan Vegetasi Atas (\%)

Gambar 4. Pengaruh kerapatan vegetasi atas terhadap erosi tanah pada penggunaan lahan semak belukar dan hutan sekunder Kecamatan Kairatu

Hal ini menunjukkan bahwa semakin meningkatnya kerapatan vegetasi bawah pada penggunaan lahan semak belukar dan hutan sekunder, maka tingkat degradasi tanah melalui peristiwa erosi semakin menurun, atau sebaliknya dengan semakin berkurangnya kerapatan vegetasi bawah, maka degradasi tanah semakin meningkat.

Dapat dijelaskan bahwa adanya vegetasi penutup bawah pada seluruh penggunaan lahan maka sangat berperan dalam mencegah erosi percikan dengan melindungi tanah dari dampak pukulan air hujan secara langsung, mengintersep curah hujan yang jatuh, mengurangi tingginya tetesan yang jatuh ke tanah yang pada dasarnya mengurangi dari kekuatan energi perusak. Selain itu juga membantu terpeliharanya konsistensi laju infiltrasi tanah dan mencegah terbentuknya lapisan kerak di permukaan., mengurangi laju dan volume aliran permukaan dengan menahan sebagian dari air itu untuk penggunaannya sendiri, membantu pengikatan agregat tanah, memperbaiki struktur tanah dan porositas oleh bahan bahan organik. Hal ini sesuai dengan beberapa hasil penelitian antara lain: menurut FAO (1999a) kehilangan penutup tanah akan mengintensifkan kerusakan tanah khususnya pada lereng-lereng curam, karena terjadi peningkatan erosi dan aliran permukaan yang ditunjukkan dengan adanya erosi alur dan parit yang sangat besar. Menurut Brandt (1988 dikutip FAO dan CIFOR, 2005) bahwa kemampuan tetesan hujan di bawah pohon untuk mengerosi tanah lebih besar. Hal ini disebabkan tetesan hujan mengumpul sebelum menetes dari dedaunan dan kemudian akan menghantam tanah dengan kekuatan yang lebih besar.
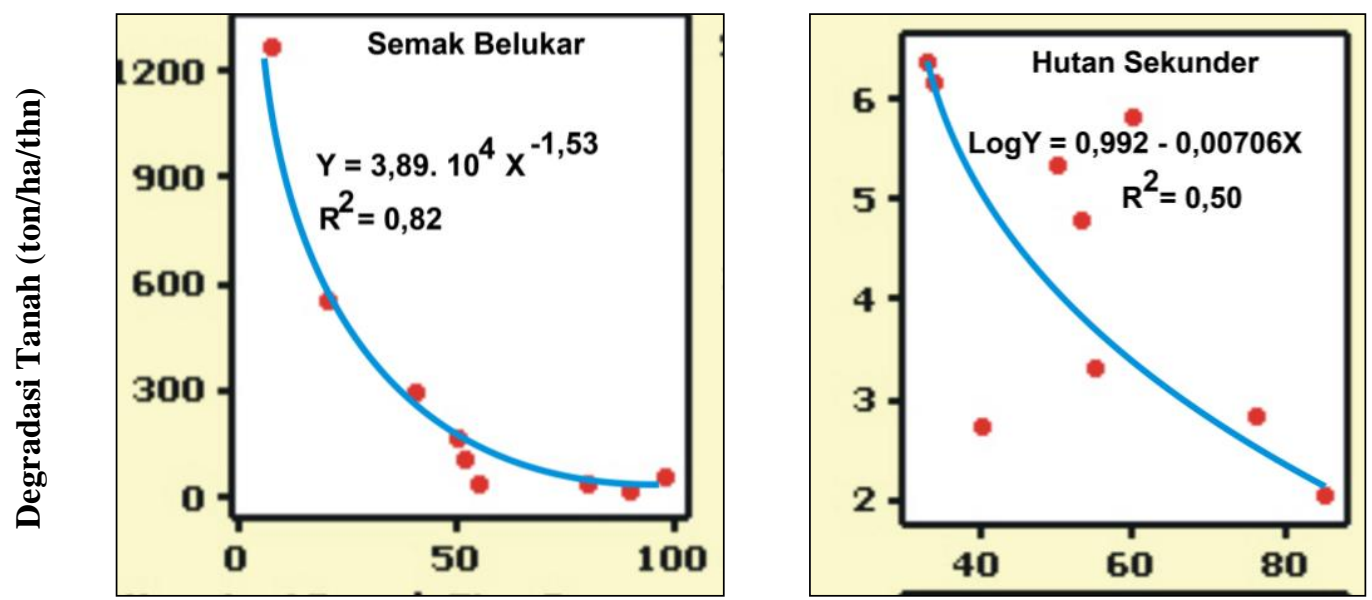

Kerapatan Vegetasi Bawah (\%)

Gambar 5. Pengaruh kerapatan vegetasi bawah terhadap erosi tanah pada penggunaan lahan semak belukar dan hutan sekunder di Kecamatan Kairatu. 
Pengaruh Faktor Penggunaan Lahan: Luas, Kerapatan Vegetasi Atas dan Kerapatan Vegetasi Bawah serta Faktor yang paling berpengaruh Terhadap Degradasi Tanah pada Semak Belukar dan Hutan Sekunder

Berdasarkan hasil penelitian dan hasil uji regresi pada penggunaan lahan hutan sekunder seperti disajikan pada, ternyata bahwa luas penggunaan lahan $\left(X_{l H S}\right)$, kerapatan vegetasi atas $\left(X_{2 H S}\right)$ dan kerapatan vegetasi bawah $\left(X_{3 H S}\right)$ berpengaruh sangat nyata $\left(\mathrm{P}=0,000^{*}\right)$ terhadap kerusakan tanah $\left(Y_{H S}\right)$ dengan koefisien determinasi $R^{2}=0,98$ dan persamaan regresinya adalah: $Y_{H S}=23,7-0,00077 X_{1 H S}-0,240 X_{2 H S}-0,0151 X_{3 H S}$. Hal ini menunjukkan bahwa dengan semakin rendah luas penggunaan lahan, berkurangnya kerapatan vegetasi atas dan berkurangnya kerapatan vegetasi bawah pada hutan primer maka kerusakan tanah semakin meningkat.

Setelah dilakukan uji regresi parsial terbaik (step wise/best subset) terhadap semua variabel $X$, maka kerapatan vegetasi atas $\left(X_{2 H S}\right)$ dan kerapatan vegetasi bawah berpengaruh nyata terhadap degradasi tanah $\left(Y_{H S}\right)$ dengan nilai-P masing-masing $\left(\mathrm{P}_{\text {parsial }} \mathrm{X}_{2 H S}=\right.$ $\left.0,000^{*}\right)$ dan $\left(\mathrm{P}_{\text {parsial }}\right.$ X3HS $\left.=0,045^{*}\right)$, dan koefisien determinasi $R^{2}=0,97$ dan persamaan regresinya adalah: $Y_{H S}=24,21-0,246 X_{2 H S}-0,0189 X_{3 H S}$. Hal ini menunjukkan bahwa dengan semakin berkurangnya kerapatan vegetasi atas dan berkurangnya kerapatan vegetasi bawah pada hutan sekunder maka kerusakan tanah semakin meningkat. Dapat dijelaskan bahwa hutan sekunder merupakan hutan yang sudah ada campur tangan atau sudah dijamah oleh manusia dalam pengelolaannya baik berupa penebangan pohon oleh perusahaan pemegang HPH dalam skala besar, maupun oleh masyarakat pedesaan untuk kebutuhan kayu bakar dan perumahan serta untuk areal pertanian masyarakat. Hutan yang tadinya memiliki kerapatan vegetasi yang tinggi maupun kerapatan vegetasi bawah yang tinggi serta serasah yang tebal, kini menjadi lebih terbuka akibat hilangnya vegetasi penutup dan baik pada strata atas maupun strata bawah termasuk serasah dan humus tanah. Akibatnya curah hujan dengan energi yang besar dapat langsung menghancurkan permukaan tanah dan meningkatkan aliran permukaan yang pada akhirnya akan meningkatkan erosi. Hal ini sesuai dengan FAO (1999c) bahwa terdapat dua komponen dari penutupan tajuk dalam mengurangi erosi yaitu penutup atas (aerial cover) dan penutup bawah (contact cover). Lebih lanjut dikatakan bahwa untuk lereng-lereng 15\%-50\% diperlukan nilai kerapatan vegetasi bawah yang tinggi yaitu lebih dari $75 \%$ untuk dapat meredusir erosi tanah. Menurut Asdak (2002) struktur vegetasi sangat berpengaruh terhadap bahaya erosi. Struktur vegetasi yang bertingkat-tingkat dapat menurunkan bahaya erosi daripada lahan dengan dominasi pohon yang kurang disertai serasah dan tumbuhan bawah. Brandt (1988 dikutip FAO dan CIFOR, 2005) menyatakan bahwa kemampuan tetesan hujan di bawah pohon untuk mengerosi tanah lebih besar. Ini disebabkan karena tetesan hujan mengumpul sebelum menetes dari dedaunan dan kemudian akan menghantam tanah dengan kekuatan yang lebih besar.

Berdasarkan hasil penelitian dan hasil uji regresi pada penggunaan lahan semak belukar, ternyata bahwa luas penggunaan lahan $\left(X_{I S B}\right)$, kerapatan vegetasi atas $\left(X_{2 S B}\right)$ dan kerapatan vegetasi bawah $\left(X_{3 S B}\right)$ berpengaruh nyata $\left(\mathrm{P}=0,000^{*}\right)$ terhadap degradasi tanah $\left(Y_{S B}\right)$ dengan koefisien determinasi $R^{2}=98,9 \%$ dan persamaan regresinya adalah: $Y_{S B}=3434+0,110 X_{I S B}-$ $64,0 X_{2 S B}-2,33 X_{3 S B}$. Setelah dilakukan uji regresi parsial terbaik (step wise/best subset) terhadap semua variabel $X$, maka kerapatan vegetasi atas $\left(X_{2 S B}\right)$ dan variabel kerapatan vegetasi bawah $\left(X_{3 S B}\right)$ berpengaruh nyata terhadap degradasi tanah $\left(Y_{S B}\right)$ dengan nilai $\mathrm{P}$ masingmasing $\mathrm{P}_{\text {parsial } X 2 S B}=0,000^{*}$ dan $\mathrm{P}_{\text {parsial } X 3 S B}=0,021^{*}$ dengan koefisien determinasi $R^{2}=98,75 \%$ dan persamaan regresinya adalah: $Y_{S B}=3493-64,3 X_{2 S B}-$ $2,78 X_{3 S B}$. Hal ini dapat dijelaskan bahwa dengan semakin berkurangnya kerapatan vegetasi atas dan berkurangnya vegetasi bawah pada semak belukar maka degradasi tanah semakin meningkat.Sejalan dengan pendapat FAO (1999b) yaitu kehilangan penutup tanah akan mengintensifkan kerusakan tanah khususnya pada lereng-lereng curam, karena terjadi peningkatan erosi dan aliran permukaan yang ditunjukkan dengan adanya erosi alur dan parit yang sangat besar. Juga sesuai dengan pendapat Field (1997 dikutip Sherbinin, 2002) yaitu bila penutup tanah bawah tidak cukup, maka akan menghasilkan erosi lembar, alur dan parit.

\section{KESIMPULAN}

Besar degradasi tanah untuk semak belukar (sebesar 285,57 ton/ha/thn) lebih tinggi dibandingkan dengan hutan sekunder (4,39 ton/ha/thn) dengan perbedaan yang nyata. Indikator degradasi tanah yang terjadi pada semak belukar adalah tinggi pedestal ratarata 1,76 $\mathrm{mm} / \mathrm{thn}$, akar terekspos $2,78 \mathrm{~mm} / \mathrm{thn}$, kedalaman alur $0,9 \mathrm{~cm} / \mathrm{thn}$, kedalaman parit $0,14 \mathrm{~m} / \mathrm{thn}$, lebih tinggi dibandingkan dengan indikator pada hutan sekunder yaitu tinggi pedestal $0,42 \mathrm{~mm} / \mathrm{thn}$, akar terekspos $0,46 \mathrm{~mm} / \mathrm{thn}$. Faktor luas penggunaan lahan berpengaruh nyata secara positif terhadap degradasi tanah pada semak belukar, dengan nilai $\mathrm{P}=0,044^{*}$, serta memiliki koefisien korelasi positif yaitu $+0,88$. Sebaliknya pada hutan sekunder berpangaruh negatif dengan nilai $\mathrm{P}=0,022 *$ serta koefisien korelasi negatif $-0,77$. Faktor kerapatan vegetasi atas berpengaruh nyata secara negatif terhadap degradasi tanah pada penggunaan lahan semak belukar dan hutan sekunder, dengan nilai-P $0,000^{*}$, serta memiliki koefisien korelasi yang negatif $-0,98$. Faktor kerapatan vegetasi bawah berpengaruh nyata secara negatif terhadap degradasi tanah pada penggunaan lahan semak belukar dan hutan sekunder, dengan nilai-P masing-masing $0,001^{*}$ dan $0,042 *$, serta memiliki koefisien korelasi negatif yaitu $-0,91$ dan $-0,71$. Secara serempak, faktor luas, kerapatan vegetasi atas dan kerapatan vegetasi bawah berpengaruh 
nyata terhadap degradasi tanah pada penggunaan lahan semak belukar dan hutan sekunder. Faktor yang paling berpengaruh terhadap degradasi tanah pada semak belukar dan hutan sekunder adalah kerapatan vegetasi atas dan kerapatan vegetasi bawah.

\section{DAFTAR PUSTAKA}

Asdak, C. 2002. Hidrologi dan Pengelolaan Daerah Aliran Sungai. Gadja Mada University Press.

Badan Perencanaan Pembangunan Daerah (Bappeda) Propinsi Maluku. 1996. Rencana Struktur Tata Ruang Propinsi Daerah Tingkat I Maluku. Fakta dan Analisis.

Draper, N.R. dan H. Smith. 1992. Analisis Regresi Terapan (Terjemahan). PT. Gramedia Pustaka Utama. Jakarta.

Dinas Kehutanan Propinsi Maluku. 1994. Peta Penggunaan Lahan Pulau Seram Propinsi Maluku skala 1: 100.000. Sebagai Hasil Penafsiran Citra Satelit (Citra Landsat False Colour Composite TM Tahun 1992 dan False Colour Composite MSS Tahun 1990).

Dissmeyer, G.E. and G.R. Foster. 1980. A Guide for Predicting Sheet and Rill Erosion on Forest Land. USDA Forest Service Southeastern Area 1720 Peachtree Road, N.W. Atlanta, Gorgia 30367.

FAO. 1995. Global and National Soils and Terrain Digital Databases (SOTER). Prosedures Manual. Land and Water Development Devision. World Soil Resources Reports No. 74 Rev.1

FAO. 1996. Population Change-Natural ResourcesEnvironment Linkages In East and Southeast Asia. Prepared by the Population Information Network (POPIN) of the United Nations Population Division, Department for Economic and Social Information and Policy Analysis. FAO Population Programme Service, Rome.

FAO. 1999a. New Concepts and Approaches to Land Management in The Tropics with Emphasis on Steeplands. FAO Soil Bulletin 75. Land and Water Publication Series. Land and Water Development Devision.

FAO. 1999b. Land and Crop Management in the Hilly Terrains of Central America: Lessons Learned and Farmer to Farmer Transfer of Technologies. FAO Soil Bulletin 76e. Land and Water Publication Series. Land and Water Development Devision.

FAO. 1999c. Land and Crop Management in the Hilly Terrains of Central America: Lessons Learned and Farmer to Farmer Transfer of Technologies. FAO Soil Bulletin 76e. Land and Water Publication Series. Land and Water Development Devision.

FAO dan CIFOR. 2005. Hutan dan Banjir. Tenggelam Dalam Suatu Fiksi Atau Berkembang Dalam Fakta. RAP Publication 2005/3. Forest
Perspective 2. Food and Agriculture Organization - Centre of International Forestry Research.

Kelompok Kerja Erosi dan Sedimentasi. 2002. Kajian Erosi dan Sedimentasi Pada DAS Teluk Balikpapan Kalimantan Timur. TE-02/13-I CRC/URI CRMP Proyek Pesisir Kaltim Balikpapan J1. R.E. Martadinata No. 3 RT.28 RW. 10 Kelurahan Mekarsari Balikpapan 76121, Indonesia.

Kokh-Shrestha, M. 2002. Soil Erosion Modelling Using Remote Sensing and GIS: A Case Study of Jhikhu Khola Watershed, Nepal. Part of M.Tech. Thesis Submitted to Andhra University.

Majule, A.E. 2003. Impact of Land Use/Land Cover Changes on Soil Degradation and Biodiversity on the Slopes of Mount Kilimanjaro. Tanzania. Land Use Change Impact and Dynamics Working Paper Series Number 26. Institute of Resource Assessment University of Dar es Salaam. P.O. Box 35097. Dar es Salaam. Tanzania.

Morrison, D.F. 1976 Multivariate Statistical Methods. Second Edition. Mc.Graw-Hill Book Company. New York St. Louis San Francisco Auckland Düsseldorf Johannesburg Kulala Lumpur London Mexico Montreal New Delhi Panama paris São Paulo Singapore Sydney Tokyo Toronto.

Sandy, I.M. 1977. Penggunaan Tanah (Land Use) di IndonesiaPublikasi No. 75 Direktorat Tata Guna Tanah. Departemen Dalam Negeri. Jakarta

Sherbinin. 2002. Guide to Land-Use and Land-Cover Change (LUCC) Center for International Earth Science Information Network (CIESIN) Columbia University Palisades, NY, USA. A collaborative effort of SEDAC and the IGBP/IHDP LUCC Project.

Stocking, M. and N. Murnaghan. 2000. Land Degradation Guidelines for Field Assessment. Overseas Development Group University of East Anglia Norwich, UK Co-operating Institutions: United Nations Environment Programme (UNEP), United Nations University (UNU). People, Land Management and Environmental Change Project (PLEC)Japan.

Symeonakis, E., S. Koukoulas, A. Calvo-Cases, E. Arnau-Rosalen, and I. Makris. 2004. A Landuse Change and Land Degradation Study in Spain and Greece Using Remote Sensing and GIS. Departamento de Geografía, Universidad de Valencia, Av. Blasco Ibáñez 28, Valencia 46010, Spain, Dept. of Geography, University of the Aegean, Mytilene 81100, Greece.

Swiecki, T.J. and E.A. Bernhardt. 2001. Guidelines for Developing and Evaluating Tree Ordinances. 
USDA Forest Service through the National Urban and Community Forestry Advisory Council and the International Society of Arboriculture.
Talakua, S.M. 2009. Pengaruh Penggunaan Lahan Terhadap Kerusakan Tanah Karena Erosi Di Kecamatan Kairatu Kabupaten Seram Bagian Barat Propinsi Maluku. Disertasi Program Pascasarjana Universitas Padjadjaran Bandung. 